\title{
Sorafenib Reveals Anti-Arthritic Potentials in Collagen Induced Experimental Arthritis Model
}

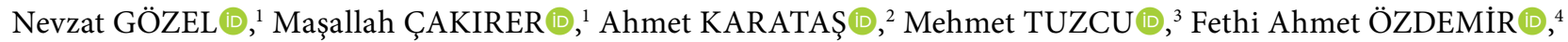 \\ Adile Ferda DAĞLI (D, ${ }^{5}$ Kazım ŞAHIN (D), ${ }^{6}$ Süleyman Serdar KOCA (D) ${ }^{2}$ \\ ${ }^{1}$ Department of Internal Medicine, Firat University Faculty of Medicine, Elazığ, Turkey \\ ${ }^{2}$ Department of Rheumatology, Firat University Faculty of Medicine, Elazı̆̆, Turkey \\ ${ }^{3}$ Department of Medical Biology, Firat University Faculty of Medicine, Elazı̆̆, Turkey \\ ${ }^{4}$ Department of Molecular Biology and Genetics, Bingöl University, Bingöl, Turkey \\ ${ }^{5}$ Department of Pathology, Fırat University Faculty of Medicine, Elazığ, Turkey \\ ${ }^{6}$ Department of Animal Nutrition, Firat University Faculty of Medicine, Elazı̆̆, Turkey
}

\section{ABSTRACT}

Objectives: This study aims to examine the effects of sorafenib on a collagen-induced arthritis (CIA) model.

Materials and methods: The study included 50 randomly selected female Wistar-albino rats (8-10-week-old, weighing between $200 \mathrm{~g}$ to $250 \mathrm{~g}$ ). The rats were divided into five equal groups as control, arthritis, etanercept, sorafenib high-dose, and sorafenib low-dose groups, respectively. Arthritis was induced by injecting mixed intradermal chicken type II collagen and incomplete Freund's adjuvant. Twenty-four hours after the advent of arthritis; rats in group 3 were injected subcutaneous etanercept ( $6 \mathrm{mg} / \mathrm{kg} / \mathrm{week}$ ), while those in groups 4 and 5 were given sorafenib (10 or $30 \mathrm{mg} / \mathrm{kg} / \mathrm{day}$ ) orally until they were sacrificed on the $34^{\text {th }}$ day. The rat claws and trunk bloods were carefully examined to note perisynovial inflammation and cartilage/bone injury through histopathology. Tissue vascular endothelial growth factor (VEGF) and VEGF receptor levels were carefully checked using western blot analysis.

Results: Analysis of the experimental data showed that CIA decreased in treatments groups after $12-13$ days and $34^{\text {th }}$ day in contrast with the arthritis group. Histopathological examination revealed broad perisynovial inflammation and cartilage/bone break down in the arthritis group. Compared to the control group, tissue VEGF and VEGF receptor levels increased in the arthritis group. Sorafenib and etanercept decreased tissue VEGF and VEGF receptor levels, perisynovial inflammation, damage of cartilage/bone.

Conclusion: Our findings indicate that sorafenib treatment ameliorates CIA with anti-VEGF effectiveness.

Keywords: Collagen-induced arthritis; rheumatoid arthritis; sorafenib.

Rheumatoid arthritis (RA) is an inflammatory systemic disease, which is observed in the joints and characterized by erosive synovitis. ${ }^{1,2}$ It causes progressive destruction, deformity, and disability in the joints. ${ }^{1,2}$ A majority of patients develop systemic symptoms too. Exhaustion, fatigue, loss of appetite, weight loss, and frequent musculoskeletal pain are the first non-specific complaints. ${ }^{1,2}$ Several etiological causes have been put forth such as genetic factors, infections, sex and hormonal causes, heat shock proteins and environmental factors. However, none of these causes are sufficient by themselves to explain the etiology. ${ }^{3,4}$

Clinical course is quite variable in RA. On the other hand, few patients enter remission during

Received: September 28, 2017 Accepted: November 07, 2017 Published online: November 27, 2017

Correspondence: Nevzat Gözel, MD. Fırat Üniversitesi Tıp Fakültesi İç Hastalıkları Anabilim Dalı, 23119 Elazığ, Turkey. Tel: +90 424 - 2333555 e-mail: drngozel@hotmail.com

\section{Citation:}

Gözel N, Çakırer M, Karataş A, Tuzcu M, Özdemir FA, Dağlı AF, et al. Sorafenib Reveals Anti-Arthritic Potentials in Collagen Induced Experimental Arthritis Model. Arch Rheumatol 2018;33(3):309-315. 
the first two years of the disease. Its pathogenesis has not yet been clearly revealed. None of the agents used for RA treatment eliminate the disease completely. Hence, all agents used in the treatment should be considered as palliative treatments for comforting the symptoms and findings of the disease. Various treatments are intended for the non-specific suppression of inflammatory or immunologic process with the hope of treating the complaints and preventing progressive damage on the joint structures. ${ }^{4,5}$ In principle, RA treatment is based on modifying medications. These agents provide treatments which aim to reduce or even reverse the progression of the various symptoms and findings, including disability, low life quality, or occupational insufficiency with progressively increasing joint damage, or to be effective on the course of disease as a whole. ${ }^{5}$ In recent years, cellular pathways of inflammation and various kinase pathways as therapeutic targets have attracted attention. ${ }^{6}$

Sorafenib exhibits its effect by way of inhibiting the multiple intracellular and cell surface kinases. ${ }^{7,8}$ These kinases are responsible for tumorigenesis, angiogenesis, and apoptosis. Sorafenib has been approved to treat renal cell carcinoma and hepatocellular cancer. It inhibits receptor tyrosine kinases that include vascular endothelial growth factor (VEGF) and VEGF receptor (VEGFR) and has anti-angiogenic actions. ${ }^{7,8}$ Angiogenesis or formation of new capillaries has a critical role in the pathogenesis of RA. ${ }^{9}$ To our knowledge, sorafenib has not been used in RA treatment before. Therefore, in this study, we aimed to examine the effects of sorafenib on a collageninduced arthritis (CIA) model.

\section{MATERIALS AND METHODS}

This study was conducted at Firat University, Faculty of Medicine, between January 2016 and June 2017. The study included 8-10-week-old 50 female Wistar-albino rats (weighing between $200 \mathrm{~g}$ and $250 \mathrm{~g}$ ). The temperature of the environment where the animals were kept was held constant between $22-24^{\circ} \mathrm{C}$ and they were subject to a photoperiodic regime with 12 hours of light. The rats were fed in cages in a ventilated environment with relative humidity of $55 \pm 5 \%$. All rats were subjected to standard rat feed and their proper food and water intakes were ensured. Before conducting any experiment on animals, a mandatory approval was obtained from the local Ethics Committee.

The rats were divided into five equal groups as control, arthritis, etanercept $(5 \mathrm{mg} / \mathrm{kg})$, sorafenib high-dose (30 mg/kg/day), and sorafenib lowdose $(10 \mathrm{mg} / \mathrm{kg} /$ day) group, respectively.

Type 2 collagen (Sigma-Aldrich, St. Louis, MO, USA) was mixed and dissolved in $0.1 \mathrm{M}$ acetic acid ( $1 \mathrm{mg} / \mathrm{mL}$ ). This solution was emulsified at equal ratio with incomplete Freund's adjuvant (SigmaAldrich, St. Louis, MO, USA). ${ }^{10}$ This solution was administered intradermally for induction of arthritis to rats in groups 2, 3, 4, and 5 through hind claws $(50 \mu \mathrm{g}$ in each) and their tail dorsal (100 $\mathrm{\mu g} / \mathrm{rat}$ ) (total: $200 \mu \mathrm{g} / \mathrm{rat})$. Booster injection $(100 \mu \mathrm{g} / \mathrm{rat})$ was given from the tail dorsal seven days after the first application. Following the collagen injection, all rats were evaluated every day with regard to arthritis development and clinical arthritis scoring. Clinical arthritis scoring was established by giving scores of 0-4 for each hind claw. ${ }^{11}$

Rats in group 3 were administered $5 \mathrm{mg} / \mathrm{kg} /$ week dose of etanercept (Enbrel, Pfizer, Istanbul, Turkey), subcutaneously. Rats in groups 4 and 5 were administered sorafenib (Nexavar, Bayer, Istanbul, Turkey) dissolved in $100 \mu \mathrm{L}$ saline, via peroral nasogastric catheter. Etanercept and sorafenib applications were started at the $14^{\text {th }}$ day, and continued until $33^{\text {rd }}$ day. The study was ended on $34^{\text {th }}$ day, 24 hours after the final applications.

Blood samples were harvested and hind below-knee legs were amputated. The acquired blood samples were centrifuged (3000 rpm for 10 minutes) and the serums were kept at $-20^{\circ} \mathrm{C}$ until they were used for analysis. Tissue samples were separated into two for histopathologic and western blot analyses. The portion allocated for histopathologic analyses was placed in $10 \%$ formalin solution, whereas the portion allocated for western blot analyses was placed in an aluminum foil and then kept at $-80^{\circ} \mathrm{C}$ until the day of analysis.

The formalin conserved tissue samples were decalcified using paraffin blocks with 10\% nitric acid (30 days). Thereafter, the cross-sections of these blocks were dyed with hematoxylin-eosin 


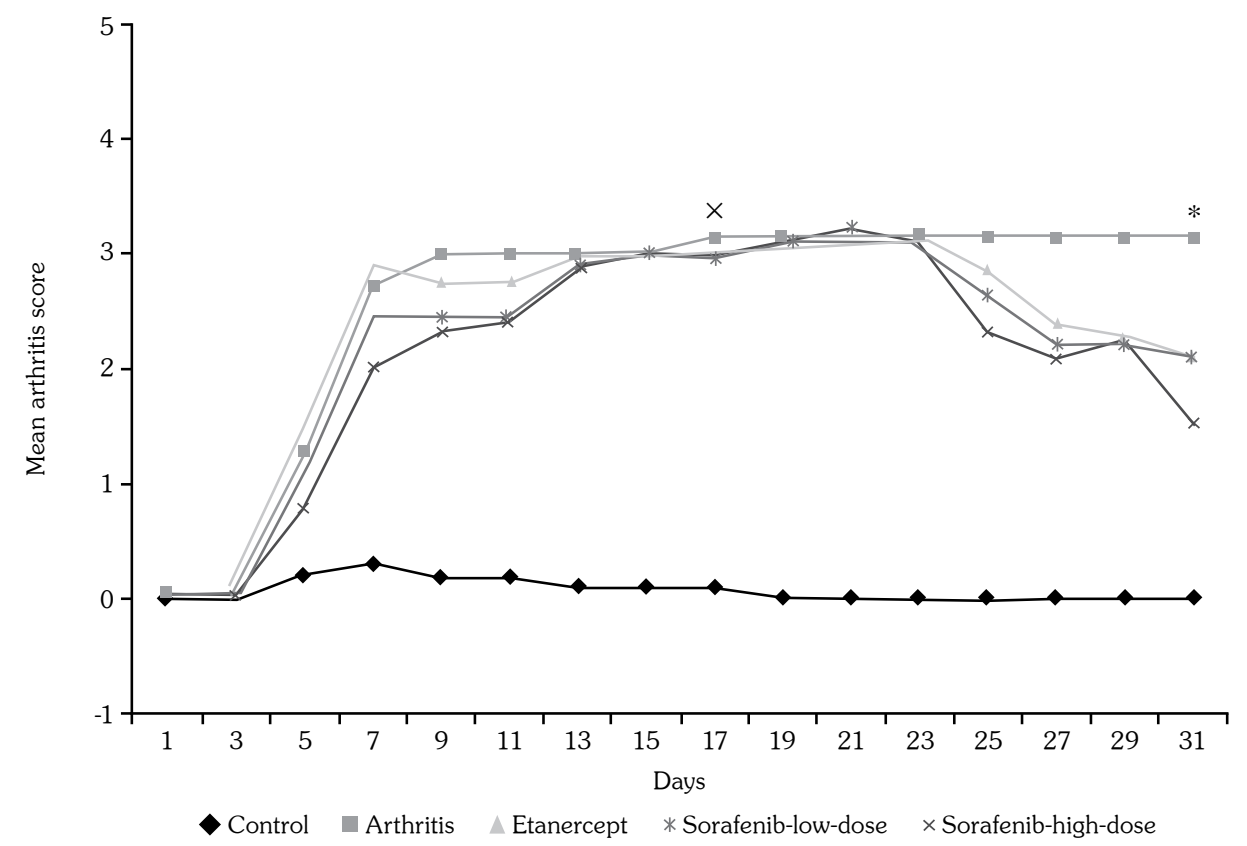

Figure 1. Daily clinical arthritis scores in all groups. $x p<0.001$ when compared with control group; * Average scores were low at a statistically significant level in all treatment groups when compared with arthritis group $(\mathrm{p}<0.05)$.

and viewed using light microscope to determine inflammatory cell infiltration and arthritis intensity. A scoring between 0-4 was established for histopathology. ${ }^{10-12}$

Western blot method was employed to study joint tissue tests for investigating expression of VEGF and VEGFR. A little sample of paw joints in each group was subjected to western blot analysis. The homogenates were set up in super

(a)

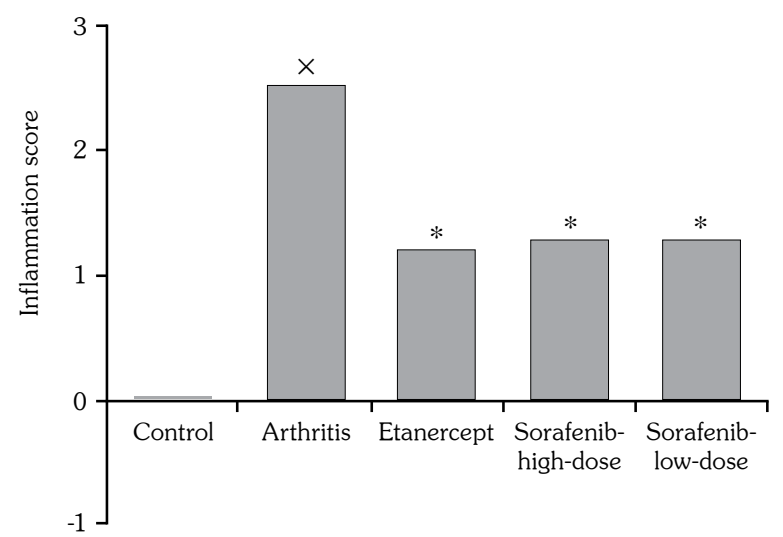

cold lysis buffer (catalyzing agent) containing $50 \mathrm{mM}$ Tris-hydrogen chloride ( $\mathrm{pH}$ 8.0), $150 \mathrm{mM}$ sodium chloride, 1\% Triton X-100, $5 \mathrm{mM}$ ethylenediaminetetraacetic acid, $0.26 \%$ sodium deoxycholate, $10 \mathrm{mM} \beta$-glycerophosphate, $50 \mathrm{mM}$ sodium fluoride, $0.1 \mathrm{mM}$ sodium orthovanadate, and $10 \mu \mathrm{g} / \mathrm{mL}$ leupeptin, $50 \mu \mathrm{g} / \mathrm{mL}$ phenylmethylsulfonyl fluoride on ice for 40 minutes $80 \mu \mathrm{L}$ of $10 \%$ Nonidet P-40 (NP-40) solution was supplemented with the suspension

(b)

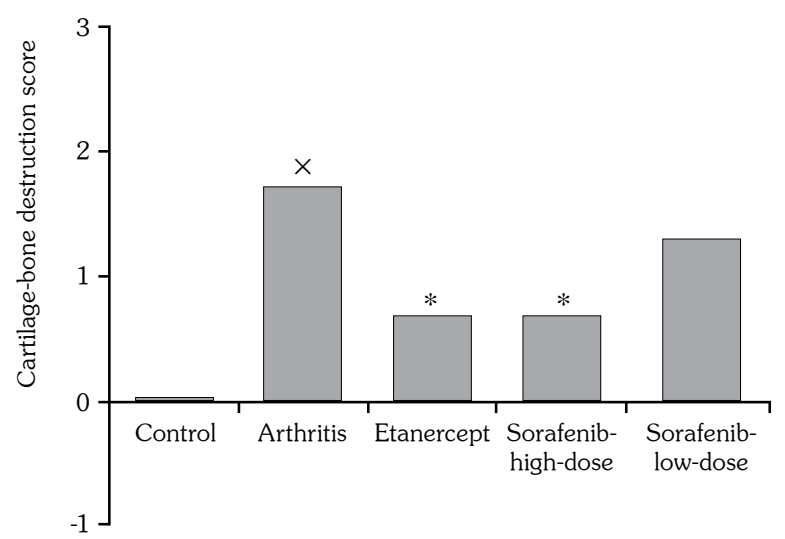

Figure 2. Histopathological inflammation and cartilage/bone destruction scores for rats with collagen induced arthritis. $\times p<0.05$ when compared with control group; ${ }^{*} p<0.05$ when compared with arthritis group. 
of homogenized tissues (homogenates), and these were centrifuged for sixty seconds at $14,000 \mathrm{~g}$ at $4^{\circ} \mathrm{C}$ to isolate protein and remove the cell debris. Protein concentration was measured according to Lowry et al. ${ }^{13}$ using a protein assay kit (SigmaAldrich, St. Louis, MO, USA). Sodium dodecyl sulfate-polyacrylamide gel electrophoresis sample buffer that contained 2\% $\beta$-mercaptoethanol was incorporated to the supernatant. Equally measured amounts of $50 \mu \mathrm{g}$ protein were subjected to electrophoresis to obtain blots, on nitrocellulose membranes (Schleicher and Schuell Inc., Keene, NH, USA). These were washed for $2 \times 5$ minutes each in phosphate-buffered saline (PBS) and fixed with 1\% cow albumin serum using PBS for 60 minutes before application of primary or main antibody. The antibodies used against VEGF and VEGFR were purchased from Abcam Inc. (Merck Millipore USA). Main antibody had a dilution of 1:1000 using the identical buffer that contained 0.05\% Tween-20. Nitrocellulose membrane was subjected to incubation for $12-14$ hours at $4^{\circ} \mathrm{C}$ using protein antibody. The blots were subjected to washing and incubation with horseradish peroxidaseconjugated goat anti-mouse immunoglobulin G (Abcam, Cambridge, UK). Desired conjugation was identified utilizing hydrogen peroxide and diaminobenzidine as substrates. Protein stacking was checked with a monoclonal mouse
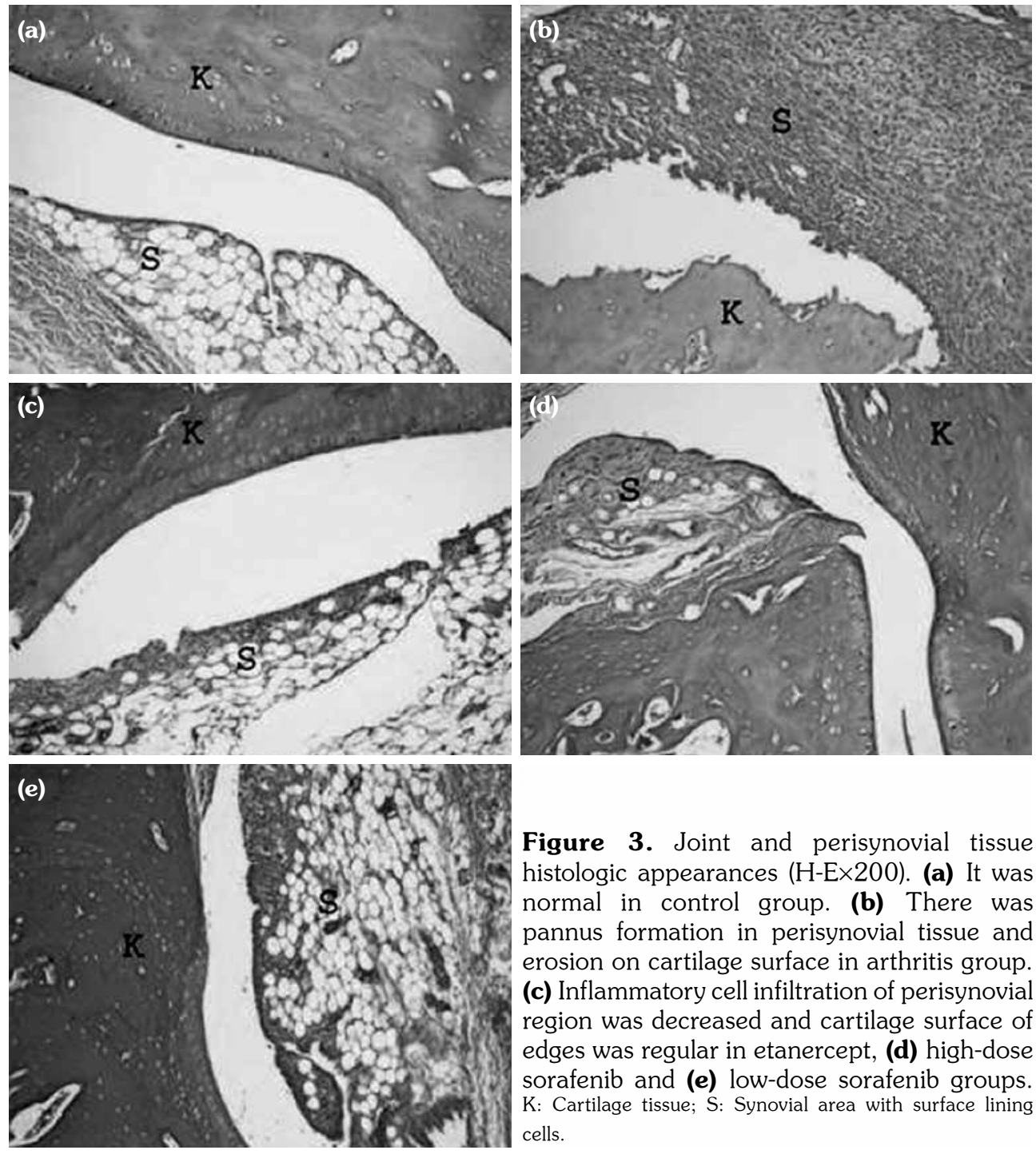

Figure 3. Joint and perisynovial tissue histologic appearances $(\mathrm{H}-\mathrm{E} \times 200)$. (a) It was normal in control group. (b) There was pannus formation in perisynovial tissue and erosion on cartilage surface in arthritis group. (c) Inflammatory cell infiltration of perisynovial region was decreased and cartilage surface of edges was regular in etanercept, (d) high-dose sorafenib and (e) low-dose sorafenib groups. K: Cartilage tissue; S: Synovial area with surface lining cells. 
(a)

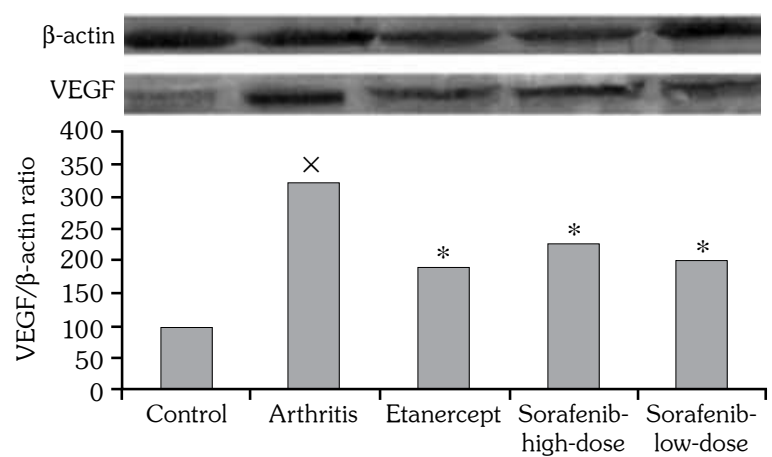

(b)

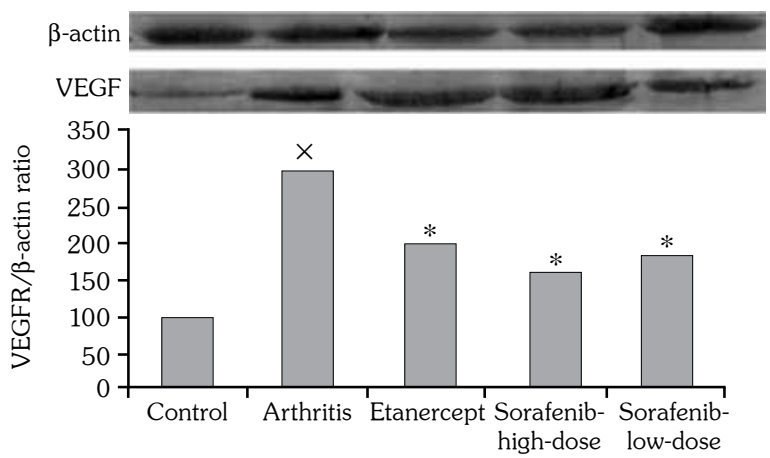

Figure 4. Histopathological inflammation and cartilage/bone destruction scores for rats with collagen induced arthritis. $\times \mathrm{p}<0.05$ when compared with control group; " $\mathrm{p}<0.05$ when compared with arthritis group.

antibody against $\beta$-actin antibody (SigmaAldrich, St. Louis, MO, USA). Blotting reaction was replicated three times to ratify the results. Densitometric examination of the bands was performed with the assistance of an image analysis program (Image J; National Institutes of Health, Bethesda, USA).

\section{Statistical analysis}

IBM SPSS Statistics version 22.0 (IBM Corp., Armonk, NY, USA) software was used for statistical analyses. The mean and standard deviation values of the data acquired in the study were calculated. Inter-group evaluation was carried out via Kruskal-Wallis and post-hoc Mann-Whitney $U$ tests. Repeated data were analyzed using Wilcoxon test. P values of $<0.05$ were considered as statistically significant.

\section{RESULTS}

Arthritis developed in all rats of groups $2,3,4$, and 5 at 12-14 days after the first collagen injection. Mean arthritis (13 ${ }^{\text {th }}$ day) scores were significantly higher in these groups compared to the control group ( $p<0.05$ for all). Arthritis continued in group 2; the $34^{\text {th }}$ day arthritis score was significantly higher in group 2 ( $p<0.05)$ compared to the control group. Mean arthritis scores of groups 3,4 , and 5 on $34^{\text {th }}$ day were significantly decreased $(p<0.05)$ compared to group 2. Moreover, $34^{\text {th }}$ day arthritis scores of groups 3,4 , and 5 were significantly decreased $(p<0.05)$ compared to their respective $13^{\text {th }}$ day scores (Wilcoxon rank) for all three groups. No statistically significant differences were noted among groups 3,4 or 5 in terms of mean arthritis scores (Figure 1).

In group 2, there was marked arthritis (Figures 2, 3a, b). Inflammatory cell infiltrations and bone damage were observed in group 2 . Mean inflammatory and cartilage/bone scores were higher in group 2 compared to the control group ( $<<0.05$ for both) (Figures 2a, b). Etanercept and sorafenib ameliorated arthritis (Figures 2 and 3). Histopathological inflammation scores were decreased in groups 3,4 , and 5 compared to group 2 ( $p<0.05$ for all). However, cartilage/bone destruction scores were decreased in groups 3 and 4 compared to group 2 ( $p<0.05$ for both). The decrease in group 5 was not statistically significant ( $p>0.05)$.

A statistically significant variance was determined in terms of VEGF and VEGFR levels in group 2 compared to group $1 \quad(p<0.05$ for both). Also, a statistically significant difference was determined between VEGF and VEGFR levels of groups 3, 4, and 5 compared to those of group 2 ( $p<0.05$ for all). However, a statistically insignificant difference was noted among groups 3,4 , and 5 with regard to VEGF and VEGFR levels (Figure 4).

\section{DISCUSSION}

In this study, the therapeutic potentials of sorafenib on experimental arthritis were researched. 
Our study showed that sorafenib ameliorated histopathological findings of arthritis. Moreover, it decreased tissue VEGF and VEGFR expressions in CIA.

The most important factor in the development of synovitis in RA is angiogenesis. Angiogenesis provides the nutrients and oxygen required for the proliferation of inflammatory cells. In RA, the mediator of angiogenesis is VEGF, which is a glycoprotein with dimeric structure. The most famous stimulants for VEGF secretion are inflammation and hypoxia, ${ }^{14,15}$ which are also the pathogenic features of RA.

A study carried out on RA patients revealed that serum and synovial fluid VEGF levels were higher compared to those of osteoarthritis patients. ${ }^{16}$ Another study indicated that angiogenesis and inflammation decreased in rats cleansed of VEGF in a CIA model. ${ }^{19-21}$ The results of our study were in accordance with the literature findings. However, while the abovementioned study used VEGF-cleansed rats, rats used in this study were not VEGF-cleansed. In this respect, both studies differ from each other. In our study, arthritis model was performed using collagen. Both studies are similar in this respect. We detected that VEGF levels in tissue homogenates of all sorafenib or etanercept administered groups were decreased in our study. So, sorafenib and etanercept showed the same effect.

It has been put forth in many studies ${ }^{17,18}$ that there are decreases in serum VEGF levels and synovial angiogenesis with infliximab infusion. Another study showed that VEGF and endotelin-1 levels are correlated with disease inflammatory indicators such as $\mathrm{C}$-reactive protein, erythrocyte sedimentation rate, and disease activity score28 in RA. Similarly, it was recorded that the high levels of VEGF were related with inflammatory indicators. It has been indicated that the generation of VEGF is excessive and that the increased serum VEGF levels are related with disease activity in RA. ${ }^{19-21}$ VEGF level is lower in RA patients who have been treated for a long time compared to newly diagnosed patients. High VEGF level in early period RA is closely related with joint damage and radiologic progression. ${ }^{22}$ Our study also demonstrated decreased arthritis scores in treatment groups administered with sorafenib or etanercept. Hence, the results of this study support the findings of the aforementioned study. The mentioned study was conducted with RA patients who had been treated for a long time; however, in our study, we used an arthritis model established in rats. In this regard, both studies differ from each other. Presence of decreased VEGF levels after treatment in the mentioned study is similar to the findings of our study.

Decreased angiogenesis mediators in patients who gave good response to standard treatment indicates that angiogenesis plays an important role in the treatment process. These data have shown the role played by angiogenesis mediators and primarily of VEGF on the evaluation of the severity and activity of the disease in inflammatory joint disease. ${ }^{9,23}$ Treatments other than anti-VEGF are currently being studied related with the inhibition of angiogenesis. Even though VEGF is considered as a good target for RA treatment, some side effects observed in anti-VEGF treatment have brought up other angiogenic factors in RA treatment; e.g., placental growth factor (PIGF) has a limited angiogenic activity with pathologic cases. It was determined that monoclonal antibodies developing against PIGF inhibit tumoral angiogenesis without showing the side effects of VEGF. ${ }^{24}$

The present study has several limitations. It documents the early effects of sorafenib and etanercept applications on arthritis; however, their long-term effects could be researched. The second, the radiographic progressions could be monitored. The study hypothesis could be analyzed in appropriate in vitro settings.

In conclusion, we have demonstrated regressed arthritis scores as well as result of sorafenib treatment with anti-VEGF effectiveness in an experimental arthritis model. Further studies are required related to the use of agents with anti-VEGF effectiveness for RA treatment in the future.

\section{Declaration of conflicting interests}

The authors declared no conflicts of interest with respect to the authorship and/or publication of this article.

\section{Funding}

This study was supported by Firat University Scientific Research Projects Coordination Unit (FUBAP). 


\section{REFERENCES}

1. Rindfleisch JA, Muller D. Diagnosis and management of rheumatoid arthritis. Am Fam Physician 2005;72:1037-47.

2. Ngian GS. Rheumatoid arthritis. Aust Fam Physician 2010;39:626-8.

3. Scott DL, Wolfe F, Huizinga TW. Rheumatoid arthritis. Lancet 2010;376:1094-108.

4. Oliver JE, Silman AJ. Risk factors for the development of rheumatoid arthritis. Scand $J$ Rheumatol 2006;35:169-74.

5. Sethi MK, O'Dell JR. Combination conventional DMARDs compared to biologicals: what is the evidence? Curr Opin Rheumatol 2015;27:183-8.

6. MacFarlane LA, Todd DJ. Kinase inhibitors: the next generation of therapies in the treatment of rheumatoid arthritis. Int J Rheum Dis 2014;17:359-68.

7. Keating GM. Sorafenib: A Review in Hepatocellular Carcinoma. Target Oncol 2017;12:243-53.

8. Ma R, Chen J, Liang Y, Lin S, Zhu L, Liang X, et al. Sorafenib: A potential therapeutic drug for hepatic fibrosis and its outcomes. Biomed Pharmacother 2017;88:459-68

9. Paleolog EM. Angiogenesis in rheumatoid arthritis. Arthritis Res 2002;4:81-90.

10. Choi J, Yoon BJ, Han YN, Lee KT, Ha J, Jung HJ, et al. Antirheumatoid arthritis effect of Rhus verniciflua and of the active component, sulfuretin. Planta Med 2003;69:899-904

11. Larsson P, Kleinau S, Holmdahl R, Klareskog L. Homologous type II collagen-induced arthritis in rats. Characterization of the disease and demonstration of clinically distinct forms of arthritis in two strains of rats after immunization with the same collagen preparation. Arthritis Rheum 1990;33:693-701.

12. Barsante MM, Roffê E, Yokoro CM, Tafuri WL, Souza DG, Pinho V, et al. Anti-inflammatory and analgesic effects of atorvastatin in a rat model of adjuvantinduced arthritis. Eur J Pharmacol 2005;516:282-9.

13. Lowry OH, Rosebrough NJ, Farr AL, Randall RJ. Protein measurement with the Folin phenol reagent. J Biol Chem 1951;193:265-75.

14. Taylor PC. VEGF and imaging of vessels in rheumatoid arthritis. Arthritis Res 2002;4:99-107.
15. Kowanetz M, Ferrara N. Vascular endothelial growth factor signaling pathways: therapeutic perspective. Clin Cancer Res 2006;12:5018-22.

16. Lee SS, Joo YS, Kim WU, Min DJ, Min JK, Park SH, et al. Vascular endothelial growth factor levels in the serum and synovial fluid of patients with rheumatoid arthritis. Clin Exp Rheumatol 2001;19:321-4.

17. Nagashima M, Wauke K, Hirano D, Ishigami $S$, Aono $\mathrm{H}$, Takai M, et al. Effects of combinations of anti-rheumatic drugs on the production of vascular endothelial growth factor and basic fibroblast growth factor in cultured synoviocytes and patients with rheumatoid arthritis. Rheumatology (Oxford) 2000;39:1255-62.

18. Kucharz EJ, Gozdzik J, Kopec M, Kotulska A, Lewicki M, Pieczyrak R, et al. A single infusion of infliximab increases the serum endostatin level in patients with rheumatoid arthritis. Clin Exp Rheumatol 2003;21:273-4.

19. Koch AE, Harlow LA, Haines GK, Amento EP, Unemori EN, Wong WL, et al. Vascular endothelial growth factor. A cytokine modulating endothelial function in rheumatoid arthritis $\mathrm{J}$ Immunol 1994;152:4149-56.

20. Harada M, Mitsuyama K, Yoshida H, Sakisaka S, Taniguchi E, Kawaguchi T, et al. Vascular endothelial growth factor in patients with rheumatoid arthritis. Scand J Rheumatol 1998:27:377-80.

21. Fava RA, Olsen NJ, Spencer-Green G, Yeo KT, Yeo $\mathrm{TK}$, Berse B, et al. Vascular permeability factor/ endothelial growth factor (VPF/VEGF): accumulation and expression in human synovial fluids and rheumatoid synovial tissue. J Exp Med 1994;180:341-6.

22. Sone $H$, Sakauchi M, Takahashi A, Suzuki H, Inoue $\mathrm{N}$, Iida $\mathrm{K}$, et al. Elevated levels of vascular endothelial growth factor in the sera of patients with rheumatoid arthritis correlation with disease activity. Life Sci 2001;69:1861-9.

23. Ballara S, Taylor PC, Reusch P, Marmé D, Feldmann $\mathrm{M}$, Maini RN, et al. Raised serum vascular endothelial growth factor levels are associated with destructive change in inflammatory arthritis. Arthritis Rheum 2001;44:2055-64

24. Luttun A, Tjwa M, Carmeliet P. Placental growth factor (PIGF) and its receptor Flt-1 (VEGFR-1): novel therapeutic targets for angiogenic disorders. Ann N Y Acad Sci 2002;979:80-93. 